ISSN 1980-5098

\title{
TROCAS GASOSAS DE PLANTAS JOVENS DE TAXI-BRANCO SUBMETIDAS À VARIAÇÃO DE TEMPERATURA FOLIAR E SUSPENSÃO DA IRRIGAÇÃO
}

\section{GAS EXCHANGE OF SEEDLINGS OF TAXI-BRANCO SUBMITTED TO LEAF TEMPERATURE VARIATION AND IRRIGATION SUSPENSION}

\author{
Ronaldo Ribeiro de Morais ${ }^{1}$ Luiz Marcelo Brum Rossi ${ }^{2}$ Rosana Clara Victoria Higa ${ }^{3}$
}

\begin{abstract}
RESUMO
O objetivo deste trabalho foi investigar a influência da variação de temperatura foliar associada à suspensão de irrigação sobre as trocas gasosas de plantas jovens de taxi-branco (Sclerolobium paniculatum Vogel). $\mathrm{O}$ estudo foi realizado em casa de vegetação na área experimental da Embrapa Amazônia Ocidental. As plantas cresceram em casa de vegetação e depois de quatro meses de aclimatização foram submetidas a três regimes hídricos (mantidas irrigadas até a capacidade de campo do solo, irrigação suspensa por oito e 14 dias). Foram avaliados os parâmetros fisiológicos de trocas gasosas, taxa de assimilação líquida de $\mathrm{CO}_{2}$ $(A)$, transpiração foliar $(E)$, condutância estomática $\left(g_{\mathrm{s}}\right)$ e eficiência no uso da água (EUA) os quais foram obtidos por meio do medidor portátil de fotossíntese (CI-340, CID, Inc.). Os resultados mostraram que houve redução das taxas de assimilação líquida de $\mathrm{CO}_{2}$ em função da elevação da temperatura foliar e da suspensão da irrigação. Após oito dias de suspensão da irrigação houve redução das taxas de assimilação líquida de $\mathrm{CO}_{2}$ fotossintéticas em $62,65,75,58,50$ e $64 \%$ e aos 14 dias esta redução foi de 80, 85, 85, 84,86 e 93\% em comparação as plantas mantidas irrigadas, nas temperaturas de $25,30,35,40,45$ e $50^{\circ} \mathrm{C}$, respectivamente. $\mathrm{O}$ comportamento das taxas de transpiração foliar foi inversamente proporcional às taxas de fotossíntese líquida, mostrando incremento em função do aumento da temperatura foliar. $\mathrm{O}$ comportamento fisiológico de trocas gasosas de Sclerolobium paniculatum apresentou variações tanto em relação ao efeito da temperatura foliar, quanto da suspensão de irrigação.
\end{abstract}

Palavras-chave: Sclerolobium paniculatum; fotossíntese; estresse hídrico.

\begin{abstract}
The study aimed to investigate the influence of leaf temperature variation associated with irrigation suspension on gas exchange of seedlings of Sclerolobium paniculatum Vogel. The study was carried out in a greenhouse at experimental area of Embrapa, Amazônia Ocidental. Plants were grown in a greenhouse and, after four months were subjected to three treatments (irrigated maintained until the field capacity, irrigation suspended for eight and 14 days). We evaluated the physiological parameters of gas exchange, net assimilation rate of $\mathrm{CO}_{2}(\mathrm{~A})$, leaf transpiration (E), stomatal conductance $\left(g_{\mathrm{s}}\right)$ and water use efficiency (WUE) which were obtained through a photosynthesis portable meter (CI-340, CID, Inc). The results showed reduction of net assimilation rate of $\mathrm{CO}_{2}$ depending on the elevation of the leaf temperature and without irrigation. After eight days without irrigation, decreased rates of photosynthetic assimilation of $\mathrm{CO}_{2}$ in 62 , $65,75,58,50$ and $64 \%$, and after 14 days the reduction was $80,85,85,84,86$ and $93 \%$ compared to plants irrigated maintained at temperatures of $25,30,35,40,45$ and $50{ }^{\circ} \mathrm{C}$, respectively. The leaf transpiration was inversely proportional to rates of net photosynthetic assimilation of $\mathrm{CO}_{2}$, which has increased with an increased leaf temperature. The physiological behavior of gas exchange of Sclerolobium paniculatum

1 Biólogo, Dr., Pesquisador da Embrapa Amazônia Ocidental, Rod. AM-010, km 29, s/n, Zona Rural, Caixa Postal 319, CEP 69010-970, Manaus (AM), Brasil. ronaldo.morais@embrapa.br

2 Engenheiro Florestal, Dr., Pesquisador da Embrapa Amazônia Ocidental, Rod. AM-010, km 29, s/n, Zona Rural, Caixa Postal 319, CEP 69010-970, Manaus (AM), Brasil. marcelo.rossi@embrapa.br

3 Engenheira Agrônoma, Dr ${ }^{\mathrm{a}}$., Pesquisadora da Embrapa Florestas, Estrada da Ribeira, km 11, Guaraituba, Caixa Postal 319, CEP 83411-000, Colombo (PR), Brasil. rosana.higa@embrapa.br
\end{abstract}

Recebido para publicação em 20/06/2013 e aceito em 21/07/2015

Ci. Fl., v. 27, n. 1, jan.-mar., 2017 
showed variations both as regards to the effect of leaf temperature as the suspension of irrigation. Keywords: Sclerolobium paniculatum; photosynthesis; water stress.

\section{INTRODUÇÃO}

Dentre as espécies de interesse econômico que evidenciam grande potencial silvicultural podemos citar o taxi-branco (Sclerolobium paniculatum Vogel), pela produção de madeira de boa qualidade para carvão, além de sua capacidade de associação com bactérias fixadoras de $\mathrm{N}$ atmosférico, rápido crescimento e elevada deposição de folhas, possibilitando rápida formação de serrapilheira, mesmo em solos álicos e de baixa fertilidade (DIAS; BRIENZA JUNIOR; PEREIRA, 1995; SOUZA et al., 2004).

De acordo com Carpenezzi et al. (1983), o Sclerolobium paniculatum ocorre em pontos da Amazônia brasileira, no Peru, no Suriname, nas Guianas e na Venezuela. No Brasil, segundo os autores, Sclerolobium paniculatum ocorre em área de terra firme.

Contudo, os estudos sobre as espécies florestais da Amazônia de rápido crescimento são muito escassos, quando se refere à influência de fatores abióticos sobre a ecofisiologia das espécies. Estes estudos são importantes para a identificação precoce das diferentes estratégias e mecanismos de adaptação da espécie em relação a sua produtividade para recomendação de áreas de plantio e em função das mudanças climáticas globais e regionais.

Os efeitos das mudanças climáticas e suas alterações nos ecossistemas carecem de estudos mais aprofundados visando à avaliação dos impactos que estas mudanças possam causar tanto nos sistemas naturais, quanto na produção agrícola/florestal em escala regional.

Estresses abióticos, como a baixa disponibilidade hídrica dos solos e o incremento médio global da temperatura em escala global, são apontados como as principais causas primárias que podem afetar negativamente a produtividade de culturas em todo mundo (INTERGOVERNMENTAL PANEL ON CLIMATE CHANGE, 2007). Estes fatores abióticos comprometem e influenciam sobremaneira processos fisiológicos como a fotossíntese em relação ao uso dos recursos primários como água, temperatura, luz, $\mathrm{CO}_{2}$ e nutrientes e, consequentemente, as taxas de crescimento.

Altas temperaturas podem afetar direta e indiretamente as trocas gasosas, tanto por promover alterações na condutância estomática, quanto pelo fato de provocar mudanças e desarranjo no aparato fotossintético, causando estresse (MAXWELL; JOHNSON, 2000; COSTA et al., 2002; RIBEIRO et al., 2004; SAGE; KUBIEN, 2007). Segundo Wise et al. (2004), danos diretos ao aparato fotossintético podem ser ocasionados por altas temperaturas por provocarem alterações nas membranas dos tilacoides, alterando a organização estrutural e as propriedades físico-químicas. Altas temperaturas podem levar ao incremento da respiração mitocondrial e da fotorrespiração (PONS; WELSCHEN, 2003; DIAS; MARENCO, 2007).

A associação de fatores como altas temperaturas foliares e estresse hídrico podem reduzir drasticamente o crescimento e desenvolvimento das plantas, uma vez que, a assimilação de $\mathrm{CO}_{2}$ está vinculada com uma alta demanda de água e as mesmas requererem abastecimento de água suficiente para o seu crescimento (HELDT; PIECHULLA, 2011; QADERI; KUREPIN; REID, 2012, SILVA et al., 2013), além de tornarem mais difícil o sucesso no estabelecimento das plantas na fase juvenil (GONÇALVES et al., 2005; LIBERATO et al., 2006).

O estudo da associação de altas temperaturas e estresse hídrico é necessário para o entedimento das alterações em crescimento e as propriedades fisiológicas de plantas em resposta a temperaturas e regimes de irrigação em várias plantas e estádios de desenvolvimento (SANTOS et al., 2013; SILVA et al., 2013).

Portanto, o objetivo deste trabalho foi investigar a influência da variação de temperatura foliar associada à suspensão de irrigação sobre as trocas gasosas de plantas jovens de taxi-branco (Sclerolobium paniculatum).

\section{MATERIAL E MÉTODOS}

O experimento foi realizado em casa de vegetação, na sede da Embrapa Amazônia Ocidental, Manaus - AM. Foram utilizadas plantas jovens de taxi-branco (Sclerolobium paniculatum) com, aproximadamente, quatro meses de idade, cultivadas em sacos plásticos $(40 \mathrm{x} 40 \mathrm{~cm})$ com capacidade para $5 \mathrm{~kg}$, preenchidos 
com mistura de terriço vegetal e argila, na proporção de 3:1 (v/v).

As condições climáticas da casa de vegetação em relação à temperatura e umidade relativa foram monitoradas durante o período total do experimento. A média da temperatura mínima não foi inferior a $23^{\circ} \mathrm{C}$ obtida no horário das $6 \mathrm{~h}$ e a máxima, não ultrapassou os $34^{\circ} \mathrm{C}$ obtida às $13 \mathrm{~h}$. A umidade relativa apresentou os valores máximos no horário entre as $18 \mathrm{~h}$ e $7 \mathrm{~h}$ e os menores no período das $8 \mathrm{~h}$ às $17 \mathrm{~h}$, com valores mínimos $(66 \%)$, reportados às $13 \mathrm{~h}$. A irradiância luminosa média dentro da casa de vegetação foi de $0,1019 \mathrm{~kW} \mathrm{~m}^{-2} \mathrm{~d}^{-1}$ durante o período do experimento.

As plantas de Sclerolobium paniculatum foram aclimatizadas em casa de vegetação por um período de 120 dias e mantidas irrigadas até a capacidade de campo, apresentando uniformidade de altura (aproximadamente $50 \mathrm{~cm}$ ). Após o período de aclimatização de 30 plantas, 15 foram mantidas irrigadas até a capacidade de campo do solo, enquanto em outras 15 , a irrigação foi suspensa até a resposta fotossintética alcançar valores próximos a zero.

Os parâmetros fisiológicos de trocas gasosas quantificados no estudo foram taxa de assimilação líquida de $\mathrm{CO}_{2}(A)$, taxa de transpiração $(E)$ e condutância estomática $\left(g_{\mathrm{s}}\right)$ obtidos com medidor portátil de fotossíntese (CI-340, CID, Inc). A partir da obtenção destes dados, calculou-se a eficiência no uso da água (EUA) por meio da equação $\mathrm{EUA}=A / E$. Os dados foram coletados em folhas completamente expandidas com bom aspecto fitossanitário e situadas no terço médio da copa, no horário entre $9 \mathrm{~h}$ e $11 \mathrm{~h}$.

Os dados da curva de resposta fotossintética à variação de temperatura foram obtidos na intensidade de fluxo de fótons (PPDF) de $1000 \mu \mathrm{mol} \mathrm{m} \mathrm{m}^{-2} \mathrm{~s}^{-1}$, câmara foliar ajustada com concentração de $\mathrm{CO}_{2}$ de 380 $\mu \mathrm{mol} \mathrm{CO} \mathrm{m}^{-2} \mathrm{~s}^{-1} \mathrm{e}$ nas temperaturas de $25,30,35,40,45$ e $50^{\circ} \mathrm{C}$, obtidas por meio do módulo de controle de temperatura CI-510CS acoplado ao medidor portátil de fotossíntese (CI-340, CID, Inc). A sequência das medições foi sempre seguindo ordem crescente de intensidade de temperatura e o tempo mínimo preestabelecido para a estabilização das leituras, em cada nível de temperatura, foi de 10 minutos e o máximo de 20 minutos. Estas avaliações foram realizadas no tempo 0 (plantas irrigadas) aos 8 e 14 dias após a adaptação aos regimes hídricos estabelecidos como tratamentos (plantas irrigadas e não irrigadas).

O delineamento experimental adotado foi o inteiramente casualizado em esquema fatorial $3 \times 5$, sendo três regimes hídrico (mantidas irrigadas até capacidade de campo do solo - ICC, irrigação suspensa por oito dias - IS8 e irrigação suspensa por 14 dias - IS14) e seis temperaturas foliares $(25,30,35,40$, 45 e $\left.50^{\circ} \mathrm{C}\right)$, com 15 plantas por tratamento $(15$ repetições $)$. Os resultados foram submetidos à análise de variância, adotando-se o nível de significância de 1 e $5 \%$ para o teste de F. Procederam-se também à análise de regressão entre as variáveis de trocas gasosas e a variação das distintas temperaturas foliares, por meio de ajustes de modelos lineares e polinomiais.

\section{RESULTADOS E DISCUSSÃO}

Os resultados mostraram que com exceção da EUA, houve efeito significativo da suspensão da irrigação sobre as taxas de $A, E$ e $g_{s}$ de Sclerolobium Paniculatum e, também, efeito significativo em relação ao incremento das temperaturas foliares em todos os parâmetros de trocas gasosas, sendo este resultado similar à interação entre os fatores (Tabela 1). Em relação à análise de regressão, com exceção do parâmetro de EUA, as demais taxas de trocas gasosas apresentaram regressões lineares significativas para o efeito do regime hídrico. Em relação ao efeito das temperaturas foliares sobre as trocas gasosas, este foi significativo para a regressão linear em todos os parâmetros e significativo para o ajuste de regressões quadráticas somente para as taxas de transpiração e condutância estomática (Tabela 1).

Quando há o desdobramento das interações observa-se que houve efeito significativo para todos os parâmetros de trocas gasosas em função do regime hídrico e, também, para o desdobramento do efeito da temperatura foliar, com exceção da EUA nas temperaturas de 45 e $50^{\circ} \mathrm{C}$ (Tabela 2).

Quando se associa o efeito da elevação da temperatura e a restrição hídrica, torna-se visível a redução das taxas de assimilação líquida de $\mathrm{CO}_{2}$ das plantas jovens de taxi-branco. Resultados encontrados neste trabalho também foram observados em outras espécies arbóreas. Liberato et al. (2006), estudando o comportamento das trocas gasosas em função da suspensão da irrigação em plantas jovens de Minquartia guianensis sob condições de casa de vegetação, observaram que aos 25 dias de suspensão da irrigação houve redução significativa de 25,50 e 50\% nas respostas da fotossíntese, transpiração e condutância 
TABELA 1: Análise de variância e de regressão e significâncias dos quadrados médios (QM) do efeito de três regimes de irrigação (RI) e seis temperaturas foliares (TF), sobre a taxa de assimilação líquida de $\mathrm{CO}_{2}(A)$, taxa de transpiração $(E)$, condutância estomática $(g s)$ e eficiência no uso de água (EUA) em plantas jovens de Sclerolobium Paniculatum, $(n=15)$.

TABLE 1: Analysis of variance and regression, and significance of the mean-squares (QM) of the three irrigation regimes effect (RI) and six leaf temperatures (TF) on the net assimilation rate of $\mathrm{CO}_{2}$ (A), transpiration rate (E), stomatal conductance (gs) and the efficient use of water (EUA), in young plants of Sclerolobium Paniculatum $(n=15)$.

\begin{tabular}{lccccc}
\hline \multirow{2}{*}{ Fatores } & \multirow{2}{*}{ GL } & \multicolumn{5}{c}{ QM } \\
\cline { 3 - 6 } & 2 & $2795,26^{* *}$ & $153,94^{* *}$ & $46153^{* *}$ & $4,75^{\text {ns }}$ \\
\hline RI & 1 & $855,46^{* *}$ & $50,31^{* *}$ & $14473,83^{* *}$ & $0,50^{\text {ns }}$ \\
Regressão Linear & 1 & $77,28^{* *}$ & $0,93^{\text {ns }}$ & $912,98^{* *}$ & $1,02^{\text {ns }}$ \\
Desvio & 5 & $293,28^{* *}$ & $25,93^{* *}$ & $3172,68^{* *}$ & $794,30^{* *}$ \\
TF & 1 & $465,73^{* *}$ & $37,11^{* *}$ & $3365,37^{* *}$ & $1289,37^{* *}$ \\
Regressão Linear & 1 & $4,75^{\text {ns }}$ & $2,64^{* *}$ & $983,41^{* *}$ & $16,97^{\text {ns }}$ \\
Regressão Quadrática & 3 & $5,96^{*}$ & $1,19^{* *}$ & $313,47^{* *}$ & $5,90^{\text {ns }}$ \\
Desvio & 10 & $84,26^{* *}$ & $6,49^{* *}$ & $1467,11^{* *}$ & $110,36^{* *}$ \\
RI x TF & 252 & 1,79 & 0,26 & 49,24 & 5,73 \\
Erro & & 6,33 & 1,76 & 30,07 & 5,59 \\
Média & & 21,14 & 29,40 & 23,33 & 42,79 \\
CV (\%) & & &
\end{tabular}

Em que: **,* significativo a 1 e $5 \%$, respectivamente, ${ }^{\text {ns }}$ Não significativo.

estomática, respectivamente, comparada ao tratamento com as plantas mantidas irrigadas até que o solo atingisse a capacidade de campo.

Gonçalves, Silva e Guimarães (2009) observaram que as taxas de assimilação líquida de $\mathrm{CO}_{2}$, condutância estomática e transpiração em plantas jovens de Carapa guianensis reduziram em 88, 89 e $89 \%$, respectivamente, após 21 dias da supressão da irrigação. Albuquerque et al. (2013) observaram que a restrição hídrica de plantas jovens de Khaya ivorensis ocasionou reduções significativas na taxa de assimilação líquida de $\mathrm{CO}_{2}(90 \%)$, na condutância estomática (95\%), na transpiração (93\%) e na razão entre concentração intercelular e ambiental de $\mathrm{CO}_{2}(37 \%)$.

Em feijão-de-porco (Canavalia ensiformis), Zanella et al. (2004) verificaram também que o deficit hídrico provocou decréscimos significativos na fotossíntese, transpiração, condutância estomática e na razão $\mathrm{Ci} / \mathrm{Ca}$; comparado com o tratamento irrigado.

Pitman (1996), estudando a influência de fatores abióticos sobre a condutância estomática de Hopea ferrea, em florestas tropicais, mostrou que o potencial hídrico, seguido pela temperatura foliar, são as variáveis ambientais que tem maior influência na abertura estomática.

Avaliando-se a influência das diferentes temperaturas foliares sobre as taxas de assimilação líquida de $\mathrm{CO}_{2}$ para as plantas irrigadas (tempo 0) observou-se que o incremento da temperatura até $35^{\circ} \mathrm{C}$ não alterou significativamente as taxas fotossintéticas, podendo-se visualizar a redução desta taxa a partir da temperatura de $40^{\circ} \mathrm{C}$ (Figura 1). As menores taxas de assimilação líquida de $\mathrm{CO}_{2}$ foram reportadas para as temperaturas foliares de 45 e $50^{\circ} \mathrm{C}$. Aos oito dias após a suspensão da irrigação, a redução da taxa fotossintética já foi observada na temperatura foliar de $35^{\circ} \mathrm{C}$ e, aos 14 dias após a suspensão da irrigação, na temperatura de $25^{\circ} \mathrm{C}$, a taxa de assimilação líquida de $\mathrm{CO}_{2}$ foi menor em relação às plantas irrigadas e com 8 dias de suspensão da irrigação e com o aumento da temperatura os valores continuam baixos atingindo valores próximos a zero $(0)$ na temperatura de $50^{\circ} \mathrm{C}$.

Comparando-se o efeito dos dias de suspensão da irrigação sobre as taxas fotossintéticas em função de temperaturas foliares específicas observa-se que após oitos dias de suspensão da irrigação houve redução 
TABELA 2: Análise de variância e de regressão e significâncias dos quadrados médios (QM) do efeito de três regimes de irrigação (RI) e seis temperaturas foliares (TF), sobre a taxa de assimilação líquida de $\mathrm{CO}_{2}(A)$, taxa de transpiração $(E)$, condutância estomática $(g s)$ e eficiência no uso de água (EUA) em plantas jovens de Sclerolobium paniculatum, $(n=15)$, com desdobramento da interação regimes de irrigação $\mathrm{x}$ temperaturas foliares (RI x TF)

TABLE 2: Analysis of variance and regression, and significance of the mean-squares (QM) of the three irrigation regimes effect (RI) and six leaf temperatures (TF) on the net assimilation rate of $\mathrm{CO}_{2}$ (A), transpiration rate (E), stomatal conductance (gs) and the efficient use of water (EUA), in young plants of Sclerolobium Paniculatum $(n=15)$, with scrolling interaction irrigation $\mathrm{x}$ leaf temperature regimes (RI x TF).

\begin{tabular}{lccccc}
\hline \multirow{2}{*}{ Fatores } & GL & \multicolumn{5}{c}{$\mathrm{QM}$} \\
\cline { 3 - 6 } & 2 & $2795,26^{* *}$ & $153,94^{* *}$ & $46153^{* *}$ & $4,75^{\text {ns }}$ \\
\hline $\mathrm{RI}$ & 5 & $405,78^{* *}$ & $17,79^{* *}$ & $4110,21^{* *}$ & $270,92^{* *}$ \\
$\mathrm{TF} / 0$ & 5 & $36,61^{* *}$ & $18,73^{* *}$ & $1353,37^{* *}$ & $316,41^{* *}$ \\
$\mathrm{TF} / 8$ & 5 & $19,41^{* *}$ & $2,38^{* *}$ & $643,33^{* *}$ & $427,69^{* *}$ \\
$\mathrm{TF} / 14$ & 5 & $293,28^{* *}$ & $25,93^{* *}$ & $3172,68^{* *}$ & $794,30^{* *}$ \\
$\mathrm{TF}$ & 2 & $787,85^{* *}$ & $22,80^{* *}$ & $5836,86^{* *}$ & $274,92^{* *}$ \\
$\mathrm{RI} / 25$ & 2 & $850,35^{* *}$ & $8,48^{* *}$ & $5274,24^{* *}$ & $194,19^{* *}$ \\
$\mathrm{RI} / 30$ & 2 & $976,45^{* *}$ & $15,11^{* *}$ & $25560,41^{* *}$ & $56,78^{* *}$ \\
$\mathrm{RI} / 35$ & 2 & $323,02^{* *}$ & $78,45^{* *}$ & $7338,07^{* *}$ & $24,03^{*}$ \\
$\mathrm{RI} / 40$ & 2 & $133,65^{* *}$ & $30,50^{* *}$ & $4714,01^{* *}$ & $0,50^{\mathrm{ns}}$ \\
$\mathrm{RI} / 45$ & 2 & $145,23^{* *}$ & $31,04^{* *}$ & $4765,96^{* *}$ & $6,10^{\mathrm{ns}}$ \\
$\mathrm{RI} / 50$ & 2 & & & \\
\hline
\end{tabular}

Em que: $* * * *$ significativo a 1 e $5 \%$, respectivamente, ${ }^{\text {ns }}$ Não significativo.

das taxas fotossintéticas em $62,65,75,58,50$ e $64 \%$ e aos 14 dias, esta redução foi de $80,85,85,84,86$ e $93 \%$ para as temperaturas de $25,30,35,40,45$ e $50^{\circ} \mathrm{C}$, respectivamente (Figura 1).

De acordo com Chaves, Costa e Saibo (2011), as células-guarda dos estômatos respondem a múltiplos sinais exógenos e endógenos, como luz, concentração de $\mathrm{CO}_{2}$, deficit de vapor de pressão, entre outros e isso permite que os estômatos ajustem sua abertura muito rápida em resposta às alterações no ambiente circundante, o que contribui para otimizar o equilíbrio entre a perda de vapor de água e absorção de $\mathrm{CO}_{2}$. Ao controlar a transpiração, os estômatos também influenciam na temperatura da folha, no fluxo de metabólitos e nas sinalizações químicas à longa distância.

Além da redução da condutância estomática, outros fatores também propiciam as reduções nas taxas fotossintéticas, incluindo o aumento nas taxas de respiração, diminuição na estabilidade das membranas, decréscimo na eficiência de carboxilação da enzima Rubisco e acúmulo de carboidratos (amido) nos cloroplastos (BALDOCCHI; AMTHOR, 2001; RIBEIRO; MACHADO; OLIVEIRA, 2006; PIMENTEL; BERNACCHI; LONG, 2007; KATTGE; KNORR, 2007). É fato, para a maioria das espécies, que em temperaturas acima da ótima, que a atividade da Rubisco é afetada (WEIS; BERRY, 1988). A atividade da Rubisco é responsável por desempenhar papel importante na assimilação de carbono pelas folhas em condições de estresse. No entanto, enzimas envolvidas na regeneração da Rubisco no ciclo de Calvin também podem influenciar a taxa de assimilação de carbono (CHAVES; COSTA; SAIBO, 2011).

Comportamento similar ao da condutância estomática também foi observado para as taxas de transpiração, em todas as temperaturas testadas houve redução em função dos dias da suspensão da irrigação (Figura 1). Aos oitos dias de suspensão da irrigação, esta redução em comparação ao tempo inicial (irrigadas) foi de $77,61,59,71$ e $32 \%$ para as temperaturas de $25,30,35,40,45^{\circ} \mathrm{C}$, respectivamente. Aos 14 dias de suspensão da irrigação, a maior redução em comparação ao tempo inicial (92\%) foi reportada para a temperatura foliar de $40^{\circ} \mathrm{C}$. Este fato é explicável, pois à medida que se acentua o estresse hídrico, as plantas 

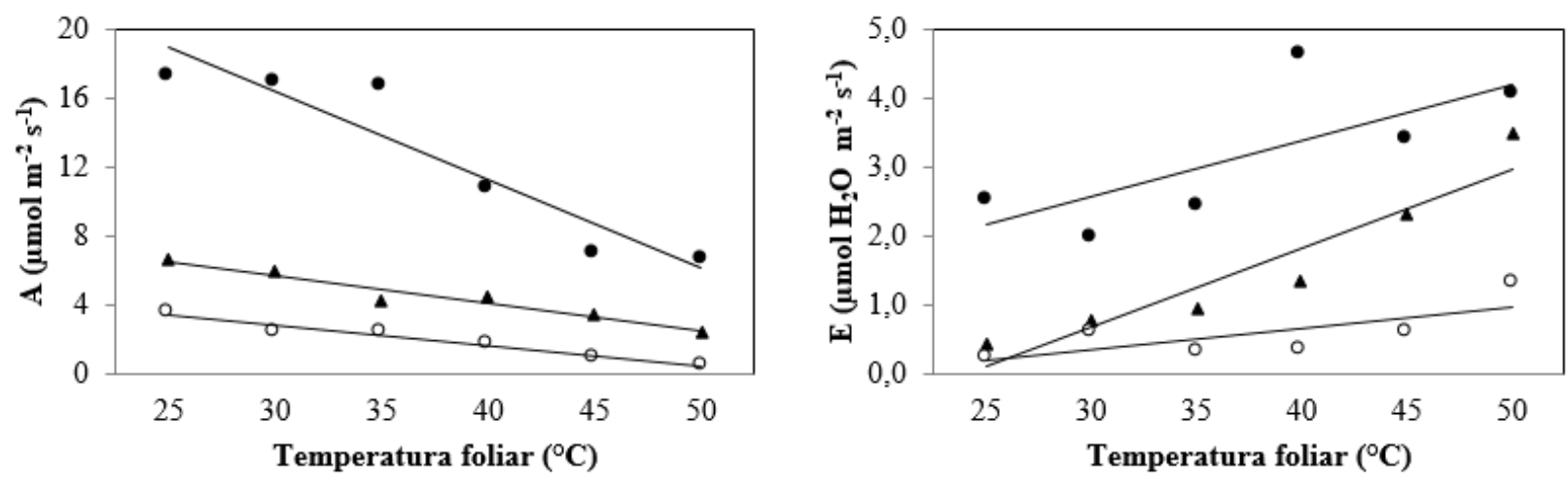

ICC - $y=-2,57 x+21,56 R^{2}=0,88$

IS8 - $y=-0,8099 x+7,31 R^{2}=0,94$

IS14 - y $=-0,6 x+4,0207 R^{2}=0,97$

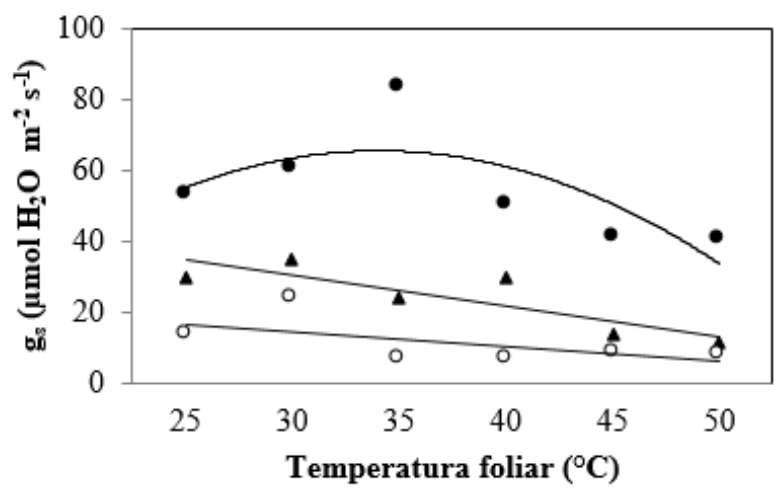

ICC - $y=-3,13 x^{2}+17,6 x+40,8 R^{2}=0,53$

IS 8 - $y=-4,2993 x+38,751 \quad R^{2}=0,71$

IS14 - $\mathrm{y}=-2,0791 \mathrm{x}+18,568 \quad \mathrm{R}^{2}=0,35$

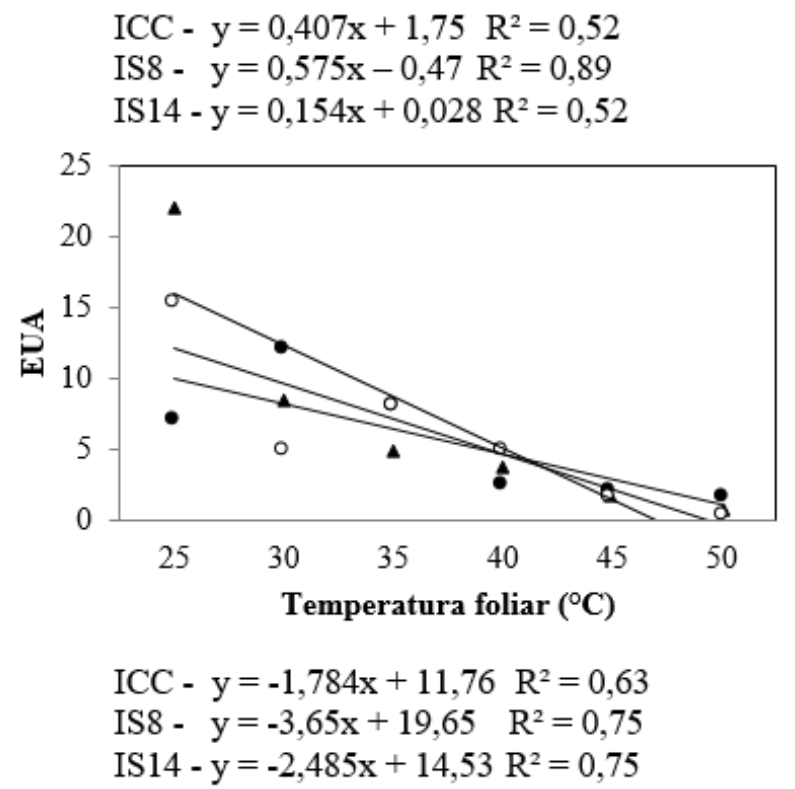

FIGURA 1: Curvas de regressão das taxa de assimilação líquida de $\mathrm{CO}_{2}(A)$, taxa de transpiração $(E)$, condutância estomática $(g s)$ e eficiência no uso de água (EUA) em resposta à variação de temperatura foliar em plantas jovens de Sclerolobium paniculatum sob três regimes hídricos (mantidas irrigadas até a capacidade de campo do solo - ICC $(\bullet)$, irrigação suspensa por oito dias - IS8 ( $\boldsymbol{\Delta}$ ) e irrigação suspensa por 14 dias - IS14 ( $\left.0^{\prime}\right)$ ). Abaixo dos gráficos encontramse as equações de ajustes das curvas para regime hídrico. $(n=15)$.

FIGURE 1: Curves of regression of net assimilation rate of $\mathrm{CO}_{2}(\mathrm{~A})$, the transpiration rate (E), and stomatal conductance (gs) and water use efficiency (WUE) according to the temperature variation of the sheet young plants of the Sclerolobium paniculatum, from three water regimes (kept irrigated to the field capacity - ICC ( $\bullet$ ), irrigation suspended for eight days- IS8 ( $\boldsymbol{\Delta})$ and irrigation suspended for 14 days- IS14 ( $\bigcirc)$ ). Below the graphs are the equations of the curve adjustments to water regime. $(n=15)$.

promovem o fechamento parcial dos estômatos como tentativa da manutenção do status hídrico favorável pelo maior tempo possível, mecanismo este, que atua contra uma possível dessecação, restringindo assim as trocas gasosas e, consequentemente, as taxas de transpiração (LARCHER, 2000).

Apesar da redução das taxas de condutância estomática e de transpiração em função dos dias de suspensão de irrigação, os resultados mostram que esta redução não restringiu a capacidade das plantas jovens de taxi-branco perderem água na forma de vapor pelas folhas em função do aumento da temperatura foliar. Este comportamento é explicável neste estudo devido à associação dos dois fatores, o estresse hídrico e o aumento da temperatura foliar, o que promoveu a elevação das taxas de transpiração foliar, servindo 
como uma estratégia utilizada para reduzir a temperatura foliar, evitando danos em função do aquecimento exagerado do aparato fotossintético, pois o processo de evaporação da molécula da água pelas plantas ocasiona uma substancial perda de calor e constitui um dos meios mais importantes que elas dispõem para regular a temperatura (TAIZ; ZEIGER, 2004). Segundo Gates (1964), taxas de transpiração na ordem de $1,84 \mathrm{mmol} . \mathrm{HZO} \cdot \mathrm{m}^{-2} \cdot \mathrm{s}^{-1}$ podem promover uma redução da temperatura foliar em até $5^{\circ} \mathrm{C}$.

Em situações extremas, a elevação da quantidade de calor nas folhas e seu tempo de exposição podem ocasionar danos ao aparato fotossintético de modo irreversível, pois pode ocorrer a desestruturação e desnaturação enzimática envolvidas no processo de assimilação de $\mathrm{CO}_{2}$, ocasionando a fotoinibição ou fotodestruição (MEDLYN; LOUSTAD; DELZON, 2002; SIEBKE et al., 2002).

O aumento da temperatura foliar também ocasiona o aumento do deficit de vapor de pressão com a diminuição da umidade relativa, intensificando o processo da transpiração (LARCHER, 2000). Os dados indicam que sem restrições da disponibilidade hídrica do solo, as taxas de transpiração são elevadas mesmo sob a influência de altas temperaturas.

\section{CONCLUSÕES}

As taxas de assimilação líquida de $\mathrm{CO}_{2}$, condutância estomática e eficiência do uso da água de plantas jovens de Sclerolobium paniculatum decresceram significativamente com a suspensão da irrigação e com o aumento da temperatura foliar.

$\mathrm{O}$ aumento da temperatura foliar propiciou o aumento das taxas de transpiração independentemente do sistema de regime hídrico, mostrando ser uma estratégia para reduzir a temperatura das folhas, evitando, assim, danos ao aparato fotossintético.

\section{REFERÊNCIAS}

ALBUQUERQUE, M. P. F. et al. Ecofisiologia de plantas jovens de mogno-africano submetidas a deficit hídrico e reidratação. Pesquisa Agropecuária Brasileira, Brasília, v. 48, n. 1, p. 9-16, 2013.

BALDOCCHI, D. D.; AMTHOR, J. S. Canopy photosynthesis: history, measurements and models. In: ROY, J.; SAUGIER, B.; MOONEY, H. A. (Ed.). Terrestrial Global Productivity. San Diego: Academic Press, 2001. p. 9-31.

CHAVES, M. M.; COSTA, M.; SAIBO, N. J. M. Recent advances in photosynthesis under drought and salinity. Advances in Botanical Research, New York, v. 57, p. 49-104, 2011.

COSTA, E. S. et al. Photochemical efficiency in bean plants (Phaseolus vulgaris L. and Vigna unguiculata L. Walp) during recovery from high temperature stress. Brazilian Journal of Plant Physiology, Campinas, v. 14, n. 2, p. 105-110, 2002.

DIAS, L. E.; BRIENZA JUNIOR, S.; PEREIRA, C. A. Taxi-branco (Sclerolobium paniculatum Vogel): uma leguminosa arbórea nativa da Amazônia com potencial para recuperação de áreas degradadas. In: KANASHIRO, M.; PARROTA, J. A. (Ed.). Manejo e reabilitação de áreas degradadas e florestas secundárias na Amazônia. Paris: UNESCO, 1995. p. 148-153.

DIAS, D. P.; MARENCO, R. A. Fotossíntese e fotoinibição em Mogno e Acariquara em função da luminosidade e temperatura foliar. Pesquisa Agropecuária Brasileira, Brasília, v. 42, n. 3, p. 305-311, 2007.

GATES, D. Leaf temperature and transpiration. Agronomy Journal, Madison, v. 56, p. 273-277, 1964.

GONÇALVES, J. F. C.; SILVA, C. E. M.; GUIMARÃES, D. G. Fotossíntese e potencial hídrico foliar de plantas jovens de andiroba submetidas à deficiência hídrica e à reidratação. Pesquisa Agropecuária Brasileira, Brasília, v. 44, n. 1, p. 8-14, 2009.

GONÇALVES, J. F. C. et al. Growth, photosynthesis and stress indicators in young rosewood plants (Aniba rosaeodora Ducke) under different light intensities. Brazilian Journal of Plant Physiology, Campinas, v. 17, p. 325- 334, 2005.

HELDT, H. W.; PIECHULLA, B. Photosynthesis implies the consumption of water. In:

Plant Biochemistry. 4th ed. Amsterdan: Elsevier, 2011. p. 211-239.

INTERGOVERNMENTAL PANEL ON CLIMATE CHANGE. Climate Change 2007: the physical 
science basis-working Group I Contribution to the IPCC Fourth Assessment Report. Brussels: IPCC, 2007. KATTGE, J.; KNORR, W. Temperature acclimation in a biochemical model of photosynthesis: a reanalysis of data from 36 species. Plant, Cell and Environment, New York, n. 30, p. 1176-1190, 2007.

LARCHER, W. Ecofisiologia Vegetal. São Carlos: RIMA, 2000.

LIBERATO, M. A. R. et al. Leaf water potential, gas exchange and chlorophyll $a$ fl uorescence in acariquara seedlings (Minquartia guianensis Aubl.) under water stress and recovery. Brazilian Journal of Plant Physiology, Campinas, v. 18, p. 315-323, 2006.

MAXWELL, K.; JOHNSON, G. N. Chlorophyll fluorescence: a practical guide. Journal of Experimental Botany, Oxford, n. 51, p. 659-668, 2000.

MEDLYN, B. E.; LOUSTAD, D.; DELZON, S. Temperature responses of parameters of a biochemically based model of photosynthesis. I. Seaasonal changes in mature maritime pine (Pinus pinaster Ait). Plant Cell and Environment, New York, v. 25, n. 9, p. 1155-1165, 2002.

PIMENTEL, C.; BERNACCHI, C.; LONG, S. Limitations to photosynthesis at different temperatures in the leaves of Citus limon. Brazilian Journal of Plant Physiology, Campinas, v. 19, n. 2, p. 141-147, 2007. PITMAN, J. I. Ecophysiology of tropical dry evergreen forest, Thailand: measured and modeled stomatal conductance of Hopea ferrea, a dominant canopy emergent. Journal of Applied Ecology, Oxford, v. 33, n. 6, p. 1366-1378, 1996.

PONS, T. L.; WELSCHEN, R. A. M. Midday depression of net photosynthesis in the tropical rainforest tree Eperua grandiflora: contributions of stomatal and internal conductances, respiration and Rubisco functioning. Tree Physiology, Oxford, n. 23, p. 937-947, 2003

QADERI, M. M.; KUREPIN, L. V.; REID, D. M. Effects of temperature and watering regime on growth, gas exchange and abscisic acid content of canola (Brassica napus) seedlings. Environmental and Experimental Botany, Elmsford, v. 75, p. 107-113, 2012.

RIBEIRO, R. V. et al. Environmental effects on photosynthetic capacity of bean genotypes. Pesquisa Agropecuária Brasileira, Brasília, v. 39, n. 7, p. 615-623, 2004.

RIBEIRO, R. V.; MACHADO, E. C.; OLIVEIRA, R. F.. Resposta da fotossíntese à temperatura e sua interação com a intensidade luminosa em discos foliares de laranjeira doce na ausência de fotorrespiração. Ciência e Agrotecnologia, Lavras, MG, v. 30, n. 4, p. 670-678, 2006.

SAGE, R. F.; KUBIEN, D. S. The temperature response of C3 and C4 photosynthesis. Plant, Cell and Environment, New York, n. 30, p. 1086-1106, 2007.

SANTOS, C. M. et al. Seasonal variations of photosynthesis, gas exchange, quantum efficiency of photosystem II and biochemical responses of Jatropha curcas L. grown in semi-humid and semi-arid areas subject to water stress. Industrial Crops and Products, Amsterdan, n. 41, p. 203-213, 2013.

SIEBKE, K. et al. Elevated $\mathrm{CO}_{2}$ increases the leaf temperature of two glasshouse-grown C-4 grasses. Functional Plant Biology, Victoria, v. 29, n. 12, p. 1377-1385, 2002.

SILVA, A. R. A. et al. Trocas gasosas em plantas de girassol submetidas à deficiência hídrica em diferentes estádios fenológicos. Revista Ciência Agronômica, Fortaleza, v. 44, n. 1, p. 86-93, 2013.

SOUZA, C. R. et al. Taxi-branco (Sclerolobium paniculatum Vogel). Manaus: Embrapa Amazônia Ocidental, 2004. 23 p.

TAIZ, Z.; ZEIGER, E. Plant Physiology. Massachusetts: Sinauer Associates, 2004. 792 p.

WEIS, E.; BERRY, J. A. Plants and high temperature stress. In: LONG, S. P.; WOODWARD, F. I. (Ed.).

Plants and temperature. Cambridge: Company of Biologists, 1988, p. 329-346.

WISE, R. R. et al. Electron transport is the functional limitation of photosynthesis in field-grown Pima cotton plants at high temperature. Plant, Cell and Environment, New York, n. 27, p. 717-724, 2004.

ZANELLA, F. et al. Photosynthetic performance in jack bean [Canavalia ensiformis (L.) D.C.] under drought and after rehydration. Brazilian Journal of Plant Physiology, Campinas, v. 16, n. 3, p. 181-184, 2004. 